\title{
Dynamics of prey selection by an omnivorous flagellate*
}

\author{
Joel C. Goldman, Mark R. Dennett \\ Woods Hole Oceanographic Institution, Woods Hole, Massachusetts 02543, USA
}

\begin{abstract}
The heterotrophic flagellate Paraphysomonas imperforata, a raptorial grazer, sustained maximum specific growth rates of $c a 1.5 \mathrm{~d}^{-1}$ at $20^{\circ} \mathrm{C}$ when fed 3 phytoplankton species of different sizes and shapes (the relatively small diatom Phaeodactylum tricornutum and haptophyte Isochrysis galbana, and the larger chlorophyte Dunaliella tertiolecta), either singularly or in combinations of 2 species. When prey combinations included $D$. tertiolecta, the chlorophyte was grazed only after a large fraction of the other species was first grazed. Diatom and haptophyte were grazed concurrently when offered in combination. Changing the relative proportions of starting biomass of the different species in combination had no effect on the order of grazing. However, in all cases the switch to the chlorophyte occurred rapidly and the maximum ingestion rate attained after the switch was proportional to the contribution of the chlorophyte to total starting biomass. From a hydrodynamic standpoint, specific clearance rate $C^{\prime}$ increased as the ratio of predator radius to prey radius $R: r$ decreased and $C^{\prime}$ increased as $R$ decreased for a given value of $\mathrm{R}$ : r. We suggest that the preference for the 2 smaller species is governed by the ability of the flagellate to adjust its own size downward to accomodate the smaller prey in order to maintain $\mathrm{R}: \mathrm{r}$ at ca $2: 1$. When sized to graze these smaller species, the flagellate simply is too small to graze the chlorophyte. Thus, although there is clear evidence that the flagellate is a non-passive grazer and will not graze certain species at all, mechanoreception clearly plays a major role in the dynamics of grazing desired species. Raptorial grazers such as $P$. imperforata by having the ability to graze prey almost as big as themselves, may be effective competitors with larger protozoa for nanoplankton-size food particles and also contribute to making the food chain (web) within the microbial loop long and complicated with high losses of energy and materials.
\end{abstract}

\section{INTRODUCTION}

In a series of recent studies, we have examined the grazing, growth, and nutrient cycling characteristics of a phagotrophic flagellate, Paraphysomonas imperforata, that is capable of both bacterivory and herbivory (Caron et al. 1985, 1986, Goldman \& Caron 1985, Goldman et al. 1985, 1987, Anderson et al. 1986). We have observed the flagellate, a raptorial feeder, to change its own size about 5 -fold by volume (ca 200 to $1000 \mu \mathrm{m}^{3}$ ) in order to accomodate a 400-fold range in prey sizes from bacteria (ca $0.5 \mu \mathrm{m}^{3}$ ) to numerous phytoplankton types and shapes, the largest of which in our experiments was the chlorophyte Dunaliella tertiolecta (ca $200 \mu \mathrm{m}^{3}$ ) (Goldman \& Caron 1985). Grazing appeared to be distinctly non-passive since no growth was observed on several phytoplankton species in the same size range as those supporting growth (Goldman \& Caron 1985).

- Contribution No. 7091 from the Woods Hole Oceanographic Institution
Judged by our results with non-axenic phytoplankton cultures, herbivory seemed to be the preferred mode of feeding by $P$. imperforata because bacterial numbers, which were as high as $10^{7} \mathrm{ml}^{-1}$, remained relatively unchanged during the course of grazing on phytoplankton (Goldman et al. 1987).

The preference for herbivory may be related to the fact that Paraphysomonas imperforata, a fairly large flagellate (diameter 7 to $12 \mu \mathrm{m}$ ) was able to maintain a relatively constant predator to prey volume ratio of ca 7 to $9: 1$ by adjusting its own size when grazing individually on different phytoplankton species in the size range 15 to $200 \mu \mathrm{m}^{3}$; yet when much smaller bacteria were the sole prey it appeared that the flagellate could only reduce its size to a lower threshold volume of about $180 \mu^{3}$ so that the predator-to-prey volume ratio was elevated to ca $360: 1$. In all cases, however, as long as individual food sources were acceptable and presented in saturating concentrations, growth rates and gross growth efficiencies of the flagellate were maximal (Goldman et al. 1985, 1987). 
Fenchel (1986) has suggested, based on simple hydrodynamic considerations and empirical evidence, that raptorial feeding among protozoa is favored when the predator-to-prey length ratio is $\leqslant 10 \cdot 1$ ( $\leqslant 1000: 1$ by volume). From our results it would appear that the optimal predator-to-prey volume ratio for a raptorial grazer such as Paraphysomonas imperforata may be far lower than 1000:1. In fact, the ability to engulf and ingest relatively large prey, in some cases prey even larger than themselves, seems to be widespread among flagellates that graze by direct interception (Goldman \& Caron 1985, Suttle et al. 1986). Many heterotrophic dinoflagellates, in particular, are capable of feeding on prey much larger than themselves (Gaines \& Taylor 1984, Jacobson \& Anderson 1986). These grazers first capture prey through attachment of a thin stalk-like filament, followed by engulfment with an emergent pseudopod that advances along the capture filament until the prey organism is totally covered by a sheathlike membrane (Jacobson \& Anderson 1986). P. imperforata similarly seems capable of engulfing prey of different shapes by extension of a very elastic outer membrane. For example, the pennate diatom Phaeodactylum tricornutum, which has a longitudinal dimension (ca $20 \mu \mathrm{m}$ ) more than twice the diameter of the flagellate (but a total volume only ca $15 \%$ that of the flagellate), once captured, is totally covered by this outer membrane, giving the odd appearance of a bulging pennate diatom (see Fig. $1 \mathrm{~A}$ in Goldman \& Caron 1985). Suttle et al. (1986) have observed an even more dramatic extension of the outer membrane of a freshwater species of Paraphysomonas (diameter 6 to $14 \mu \mathrm{m}$ ) in engulfing the pennate diatom Synedra sp. which is 40 to $85 \mu \mathrm{m}$ long. Just how this capture and engulfment occurs is completely unknown.

Raptorial grazers entrain their prey in water currents passing over the outer surface of the flagellate with capture occurring after contact with the prey is made. Frequently, we have observed multiple prey being carried along behind a single swimming Paraphysomonas imperforata cell, presumably being held by a thin filament. This filament may be the same thin stalklike structure that is used by $P$. imperforata to anchor itself to surfaces (Hibberd 1979), and, in fact, may be similar to the capture filament used by dinoflagellates.

Herbivory among raptorial-grazing flagellates (including dinoflagellates) is widespread (Goldman \& Caron 1985, Güde 1985, Jacobson \& Anderson 1986, Parslow et al. 1986, Suttle et al. 1986. Ramberg 1987. Barlow et al. 1988, Goldman et al. 1989). In fact, not only may herbivory at the flagellate level be an important component of the marine microbial food loop (Goldman \& Caron 1985, Suttle et al. 1986, Sherr et al. 1988), but the size relationships between predator and prey may be far more complicated than the simple 10.1 length relationship previously envisioned (e.g. Azam et al. 1983). To explore further the dynamics of food selection by raptorial grazers, we have expanded our earlier studies with Paraphysomonas imperforata and have performed a series of time-course grazing experiments in which combinations of 2 acceptable phytoplankton prey of different sizes and shapes and varying biomass ratios were offered as food to the flagellate. We specifically address the question of whether or not mechanoreception is an important factor in prey selection by this raptorial grazer.

\section{METHODS}

Three marine phytoplankton species, the diatom Phaeodactylum tricornutum (clone TFX-1), the chlorophyte Dunaliella tertiolecta (clone Dun), and the haptophyte Isochrysis galbana (clone T. Iso = tropical strain), all grossly different in taxonomy, size, shape and morphology, were grown in batch culture under conditions identical to those used previously (Goldman et al. 1985). Culture medium was artificial seawater (Goldman \& McCarthy 1978) with nominal additions of $200 \mu \mathrm{g}$-at. $\mathrm{I}^{-1} \mathrm{NH}_{4}^{+}$and $20 \mu \mathrm{g}$-at. $\mathrm{l}^{-1} \mathrm{PO}_{4}^{3--}$.

The heterotrophic flagellate Paraphysomonas imperforata (Lucas) (diameter 7 to $12 \mu \mathrm{m}$ ) was used in all grazing experiments. The time-course grazing experiments were designed as follows: Expt $A$ involved control experiments with single phytoplankton species and Expts B to D were, respectively, with different mixtures of Dunaliella tertiolecta and Phaeodactylum tricornutum, $D$. tertiolecta and Isochrysis galbana, and $P$. tricornutum and I. galbana. The effect on prey selection (if any) of preconditioning the flagellate on a particular food source was examined by duplicating each experiment involving mixed food sources and using inocula preconditioned on each of the prey species. Flagellate inocula for the control experiments (Expt A) were preconditioned on the respective prey species.

Cultures of each phytoplankton species (1.5 l) were grown to late exponential phase in 31 Erlenmeyer flasks under a $14: 10 \mathrm{~h}$ light-dark cycle at $20^{\circ} \mathrm{C}$. At the designated time the cultures were split according to the requirements of each experiment. Subsamples also were taken for cell counts and particulate carbon and particulate nitrogen. Each grazing experiment was performed in the dark at $20^{\circ} \mathrm{C}$ with $75 \mathrm{ml}$ of culture in $125 \mathrm{ml}$ Erlenmeyer flasks. The flasks were mixed only when sampled. Initial mixtures of phytoplankton species used in the different experiments were estimated on the basis of nitrogen biomass by the product of initial. cell counts and estimated nitrogen cell quotas $Q_{n}$ (pg $N$ cell $^{-1}$ ) based on previous experience. The desired initial phytoplankton mixtures were $33.67 \%$ 
and $67: 33 \%$ for each pair of prey species. However, some of the actual starting mixtures were different and were determined only after $Q_{n}$ was calculated for each species in the control experiments. These results were adjusted for small increases in cell numbers occurring during the first hours after cultures were placed in the dark and before grazing was measurable. Phytoplankton and flagellate cell counts were made with a Spencer Bright-line hemacytometer on samples fixed with Lugol's solution and particulate carbon and particulate nitrogen were analyzed with a Perkin-Elmer ${ }^{B}$ $240 \mathrm{C}$ elemental analyzer on samples retained on precombusted glass fiber filters (Whatman ${ }^{\circledR} \mathrm{GF} / \mathrm{F}$ ).

Monocultures or mixtures of phytoplankton were inoculated with the flagellate and sampled at 6 to $8 \mathrm{~h}$ intervals for cell counts of individual prey and predator species during the first $3 \mathrm{~d}$ and daily thereafter until the experiments were terminated at 4 to $5 \mathrm{~d}$. Measurements of flagellate specific growth rates $\mu\left(\mathrm{d}^{-1}\right)$, and ingestion rates on a cell basis $I_{p}$ (cells flag. ${ }^{-1} \mathrm{~d}^{-1}$ ) and nitrogen basis $I_{n}$ (pg $N$ flag. ${ }^{-1} \mathrm{~d}^{-1}$ ) were calculated as described previously (Goldman et al. 1989). Specific growth rates were based on regression analyses of the linear portion of plots of the natural log of cell counts versus time and ingestion rates were calculated for each interval of sampling. Curves of prey decrease or flagellate increase were drawn by visual inspection and where individual data deviated significantly from the curves, ingestion rates for that interval were calculated using the adjusted values falling directly on the curve. In most cases, this involved minor adjustments of the data. Ingestion rates on a nitrogen basis $I_{n}$ were calculated by multiplying $I_{p}$ by a constant $Q_{n}$ for each species, determined as described above, and, assuming that once cell numbers reached a maximum in the dark, $Q_{n}$ did not change while grazing occurred over the next several days. Although Paraphysomonas imperforata is not a filter feeder, equivalent clearance rates $\mathrm{C}\left(\mathrm{ml}\right.$ flag. $\left.{ }^{-1} \mathrm{~d}^{-1}\right)$ for each species were determined from the slopes of the linear portion of the curves of $I_{n}$ versus prey $N$ concentration.

\section{RESULTS}

\section{Phytoplankton characteristics}

Maximum phytoplankton cell concentrations, occurring during the initial dark phase, ranged from $6.3 \times$ $10^{5} \mathrm{ml}^{-1}$ for the largest species, Dunaliella tertiolecta $\left(200 \mathrm{\mu m}^{3}\right)$, to $3 \times 10^{6} \mathrm{ml}^{-1}$ for the smallest species Phaeodactylum tricornutum $\left(40 \mu^{3}\right)$ (Table 1). Corresponding particulate nitrogen concentrations varied from a low of $83 \mu \mathrm{g}$-at. $\mathrm{l}^{-1}$ for Isochrysis galbana (indicating that less than half of the enrichment $\mathrm{NH}_{4}^{+}$was consumed) to ca $185 \mu \mathrm{g}$-at. $\mathrm{l}^{-1}$ for the other 2 species (close to the nominal enrichment of $200 \mu \mathrm{tg}$-at. $\mathrm{l}^{-1}$ ). This led to $>4$-fold range of $Q_{n}$ values among the species from $0.84 \mathrm{pg} \mathrm{N}_{\text {cell }}^{-1}$ for $P$. tricornutum to $4.17 \mathrm{pg} \mathrm{N}$ cell $^{-1}$ for $D$. tertiolecta. The amount of nitrogen per unit cell volume $V_{n}$ remained relatively constant at ca $21 \mathrm{fg}$ $N \mu \mathrm{m}^{-3}$, however. The particulate $\mathrm{C}: \mathrm{N}$ ratios were consistent with the fraction of available $\mathrm{NH}_{4}^{+}$consumed by the 3 species, varying from $8.2: 1$ (by atoms) for $I$. galbana (representing none to slight $\mathrm{N}$-limitation) to 11.7:1 for $D$. tertiolecta (representing moderate $N$ limitation).

\section{Growth and grazing characteristics of Paraphysomonas imperforata}

A total of 13 grazing experiments were performed, 3 with the control prey species (Expt A), 4 each with prey mixtures of Dunaliella tertiolecta/Phaeodactylum tricornutum (Expt B), and D. tertiolecta/Isochrysis galbana (Expt $C$ ), and 2 with $P$. tricornutum/I. galbana (Expt D). Actual starting mixtures on a nitrogen basis in Expts $B$ and $C$ for each pair of prey species, as defined above, were ca $33 \% D$. tertiolecta: $67 \%$ P. tricornutum or I. galbana (Expts B-1 and C-1), ca $25 \%$ D. tertiolecta: $75 \%$ P. tricornutum or I. galbana (Expts B-2 and C-2), ca $67 \%$ P. tricornutum or I. galbana: $33 \%$ D. tertiolecta (Expts B-3 and C-3), and ca $75 \%$ P. tricor-

Table 1. Characteristics of phytoplankton prey species used in mixed culture experiments

\begin{tabular}{|c|c|c|c|c|c|c|}
\hline Prey species & $\begin{array}{c}\text { Approx } \\
\text { dimensions } \\
\text { (um) }\end{array}$ & $\begin{array}{c}\text { Approx } \\
\text { volume } \\
\left(\mathrm{um}^{3}\right)\end{array}$ & $\begin{array}{l}\text { Max cell } \\
\text { number } \\
\left(10^{6} \mathrm{ml}^{-1}\right)\end{array}$ & $\left(\begin{array}{c}Q_{n} \\
\left(p g \text { cell }^{-1}\right)\end{array}\right.$ & $\begin{array}{c}V_{n} \\
\left(\mathrm{fg} N \mu \mathrm{m}^{-3}\right)\end{array}$ & $\begin{array}{l}C: N \text { ratio } \\
\text { (by atoms) }\end{array}$ \\
\hline Isochrysis galbana & $5^{b}$ & 70 & 0.81 & 1.43 & 20.4 & 8.2 \\
\hline Phaeodactylum tricornutum & $2 \times 20$ & 40 & 3.00 & 0.84 & 21.0 & 9.0 \\
\hline Dunaliella tertiolecta & $6 \times 11$ & 200 & 0.63 & 4.17 & 20.9 & 11.7 \\
\hline
\end{tabular}


Fig. 1. Time course of grazing and ingestion of Paraphysomonas imperforata (•) on individual prey Phaeodactylum tricornutum (0) Dunaliella tertiolecta ( () , or Isochrysis galbana ( $\triangle$ ). (A to C) Expt A-1. (D to F) Expt A-2. (G to I) Expt A-3. $(A, D, G)$ Change in cell numbers. $(B, E, H)$ Changes in ingestion rate on cell basis. $(C, F, I)$ Changes in ingestion rate on a nitrogen basis. Symbols same in all panels
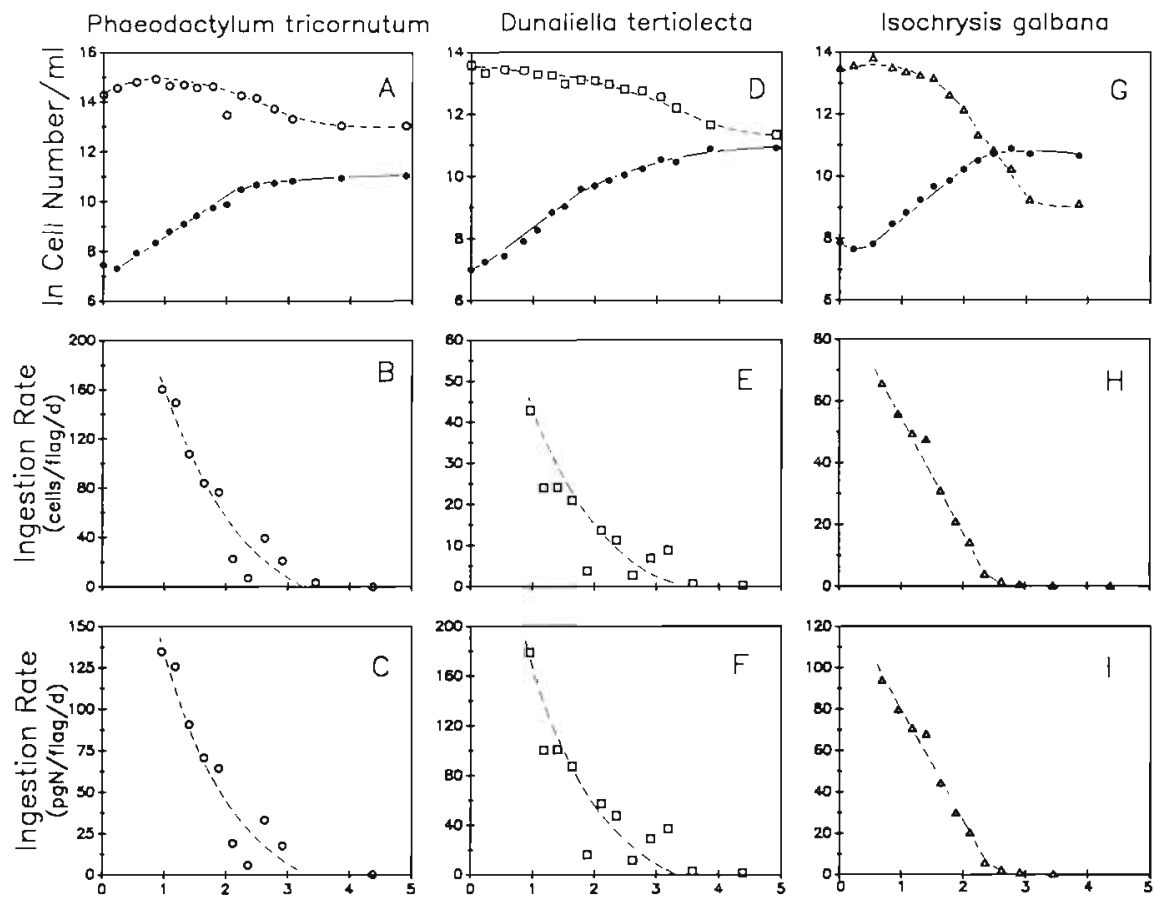

Dark Incubation Period (days)
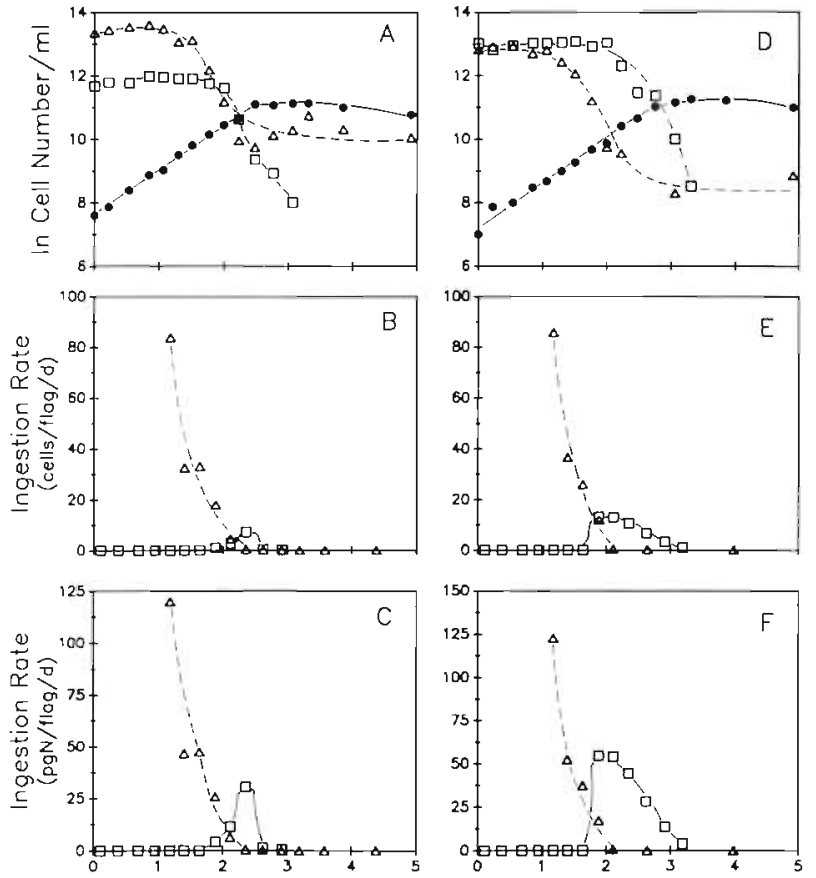

Dark Incubotion Period (days)

Fig. 2. Time course of grazing and ingestion of Paraphysomonas imperforata $(\bullet)$ on combined prey Phaeodactylum tricornutum (O) and Dunaliella tertiolecta (ㅁ). (A to C) Expt B1. (D to $F$ ) Expt B-3. (A, D) Changes in cell numbers. ( $B, E)$ Changes in ingestion rate on cell basis. (C, F) Changes in ingestion rate on nitrogen basis. Symbols same in all panels
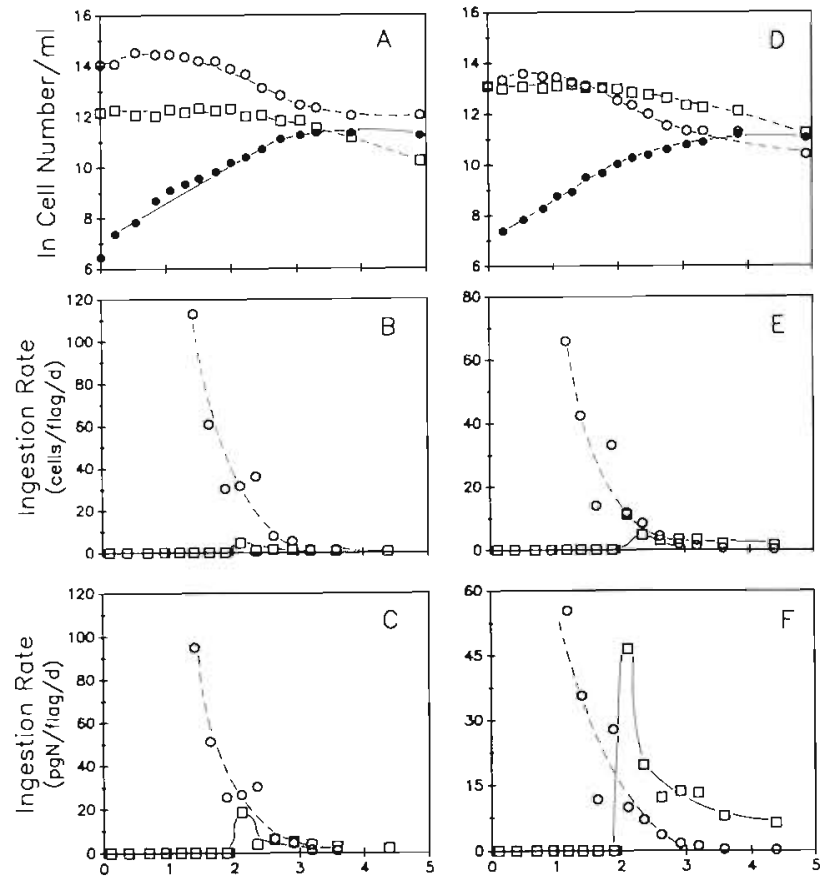

Dark Incubation Period (days)

Fig. 3. Time course of grazing and ingestion of $P_{a}$ raphysomonas imperforata $(\bullet)$ on combined prey Isochrysis galbana (:) and Dunaliella tertiolecta (a). (A to C) Expt C-1. (D to F) Expt C-3. (A, D) Changes in cell numbers, $(B, E)$ Changes in ingestion rate on cell basis. (C, F) Changes in ingestion rate on nitrogen basis. Symbols same in all panels 
between 1.5 and $2.5 \mathrm{~d}$ after the experiments began (Table 3). Grazing on $D$. tertiolecta began after 22 to $23 \%$ of either $P$, tricornutum (Expt B-4) or I. galbana (Expt C-2) was grazed and this switch occurred after only 0.8 to 1.1 d. However, since Expt B-4 represents the largest fraction of the chlorophyte mixed with the diatom, whereas Expt C-2 represents the smallest fraction of the chlorophyte mixed with the haptophyte, it is difficult to attribute any special meaning to these results.

Table 3. Fraction of $N$ biomass of either Phaeodactylum tricornutum ( $P$ ) or Isochrysis galbana (I) grazed by Paraphysomonas imperforata before switch to Dunaliella tertiolecta $(D)$ took place in Expts $B$ and $C$

\begin{tabular}{|ccc|}
\hline Expt & $\begin{array}{c}\text { Percent } P \text { or } I \\
\text { grazed } \\
(\%)\end{array}$ & $\begin{array}{c}\text { Time when switch to } D \\
\text { occurred } \\
(\mathrm{d})\end{array}$ \\
\hline B-1 & 42 & 2.0 \\
B-2 & 71 & 2.5 \\
B-3 & 59 & 2.0 \\
B-4 & 22 & 0.8 \\
C-1 & 91 & 2.0 \\
C-2 & 23 & 1.1 \\
C-3 & 82 & 2.0 \\
C-4 & 82 & 1.5 \\
\hline
\end{tabular}

The second grazing pattern we observed was that, when Dunaliella tertiolecta was the prey, the maximum value of $I_{n}$ (which always occurred soon after the flagellate switched prey; Figs. 2C, F and 3C, F) appeared to be a direct function of how much the chlorophyte contributed to total initial prey biomass (Fig. 4). In fact, in Expt B-4 maximum $\mathrm{I}_{\mathrm{n}}$ was $130 \mathrm{pg} \mathrm{N}$ flag. ${ }^{-1} \mathrm{~d}^{-1}$ when $D$. tertiolecta was prey compared to $53 \mathrm{pg} \mathrm{N}$ flag. ${ }^{-1} \mathrm{~d}^{-1}$ when Phaeodactylum tricornutum was eaten. Finally, there was no clear indication from visual inspection of the grazing curves representing Expt D (Fig. 5) that the

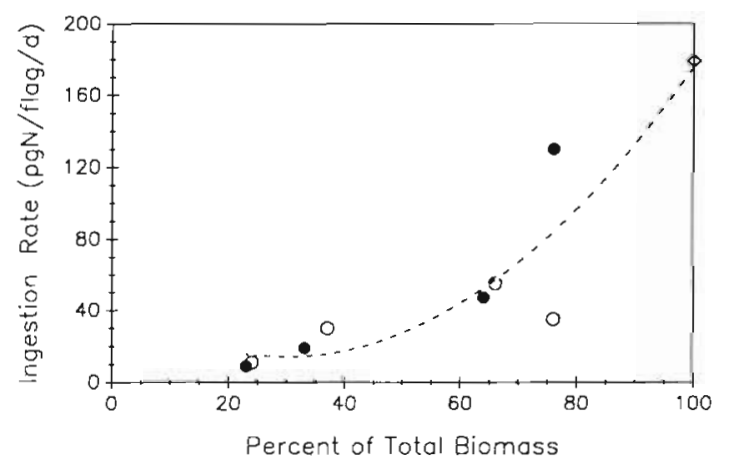

Fig. 4. Paraphysomonas imperforata. Effect of contribution to total biomass of Dunaliella tertiolecta in mixed prey cultures with Phaeodactylum tricornutum ( ) and Isochrysis galbana (1) and in control culture ( $)$ on ingestion rate on nitrogen basis
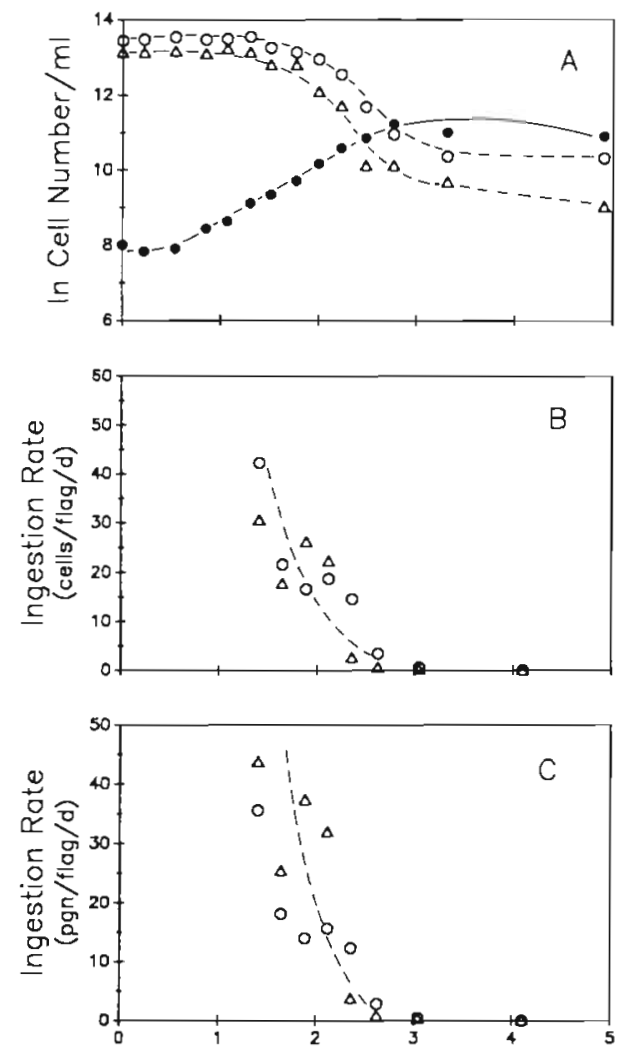

\section{Dark Incubation Period (days)}

Fig. 5. Time course of grazing by Paraphysomonas imperforata $(\bullet)$ on combined prey Phaeodactylum tricornutum (o) and Isochrysis galbana ( $)$. (A to C) Expt D-1. (A) Changes in cell numbers. (B) Changes in ingestion rate on cell basis. (C) Changes in ingestion rate on nitrogen basis. Symbols same in all panels

flagellate displayed a food preference when the diet was a mixture of $P$. tricornutum and Isochrysis galbana (both prey species appeared to be grazed concurrently).

When the pooled data from Figs. 2, 3 and 5 were examined, there was a positive (and seemingly linear) response in $I_{n}$ to increasing prey $N$ concentration for the entire range of prey biomasses tested when either Phaeodactylum tricornutum (Fig. 6A) or Isochrysis galbana (Fig. 6C) was grazed and up to ca $2 \mathrm{mg} \mathrm{l}^{-1}$ prey $\mathrm{N}$ when Dunaliella tertiolecta was grazed (Fig. 6B). These responses occurred regardless of the combination of food sources. To analyze these relationships in a semiquantitative way, we eliminated some outlying data points from each plot (open symbols in Fig. 6), and used linear regression analysis to determine the slope (= clearance rate $\mathrm{C}$ ) and correlation coefficient ( $r$ ) for each resulting curve. The resulting clearance rates as a function of prey species were $7.5 \times 10^{-5} \mathrm{ml} \mathrm{d^{-1 }}$ for $I$. galbana $\left(\mathrm{r}^{2}=0.81\right), 4.9 \times 10^{-5} \mathrm{ml} \mathrm{d}^{-1}$ for $P$, tricornutum 

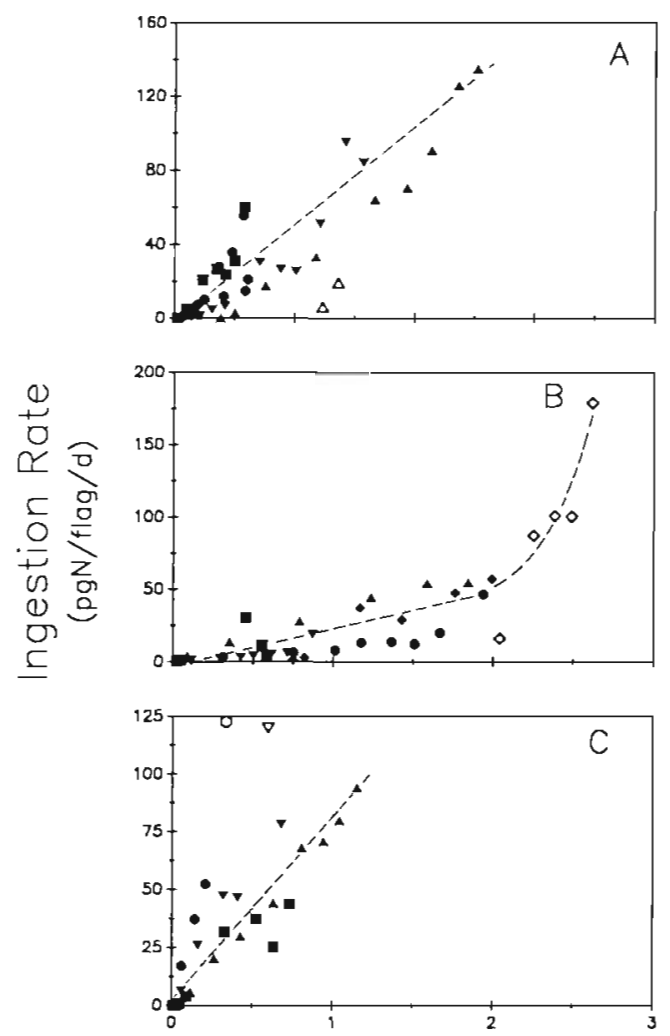

Prey Nitrogen (mg/l)

Fig. 6. Paraphysomonas imperforata. Effect of prey nitrogen biomass on ingestion rate. (A) Phaeodactylum tricornutum as

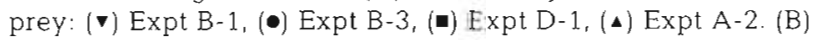

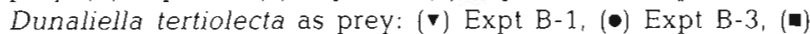
Expt C-1, (4) Expt C-3, Expt A-1. (C) Isochrysis galbana as

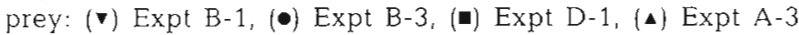
Open symbols represent data excluded from linear regression analyses summarized in Table 4

$\left(\mathrm{r}^{2}=0.88\right)$, and $2.8 \times 10^{-5} \mathrm{ml} \mathrm{d}^{-1}$ for $D$. tertiolecta $\left(\mathrm{r}^{2}=\right.$ 0.64) (Table 4). However, there was a sudden rise in the slope of the ingestion curve for the chlorophyte at prey $\mathrm{N}$ concentrations $\geqslant 2.5 \mathrm{mg} \mathrm{N}^{-1}$, indicative of a large increase in $\mathrm{C}$ at the higher prey biomass levels. Using estimates of flagellate volume $\mathrm{V}$ based on previous experiments when the prey were $D$. tertiolecta and $I$. galbana (Goldman \& Caron 1985) and a revised estimate from unpublished Coulter ${ }^{\text {(1) }}$ counter results when $P$. tricornutum was grazed, specific clearance rates $C^{\prime}$ $\left(=\mathrm{C} \mathrm{V}^{-1}\right)$ were about equal $\left(1.3\right.$ to $\left.1.4 \times 10^{5} \mathrm{~d}^{-1}\right)$ for grazing on $P$. tricornutum and 1 . galbana and considerably lower $\left(0.3 \times 10^{5} \mathrm{~d}^{-1}\right)$ when $D$. tertiolecta was grazed (Table 4). These results are consistent with the order of food preference exhibited by the flagellate, as estimated by visual inspection of the grazing curves.

Also evident was a lower limit in food concentration below which grazing and growth on each prey species ceased. This effect is seen clearly in Figs. 1 to 3 and 5 where the growth curves for Paraphysomonas imperforata leveled off and ingestion rates went to zero while prey cell concentrations still were substantial. From visual inspection of the grazing curves (Figs. 1 to 3 and 5) we estimated these lower cell numbers $T_{c}$ to be ca $4 \times 10^{4}$ to $6 \times 10^{4}$ cells $\mathrm{ml}^{-1}$ when Isochrysis galbana and Dunaliella tertiolecta were the prey to ca $1.2 \times 10^{5}$ cells $\mathrm{ml}^{-1}$ when Phaeodactylum tricornutum was grazed (Table 4). Corresponding values of $T_{n}\left(=T_{c} Q_{n}\right)$

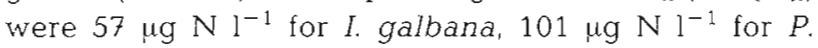

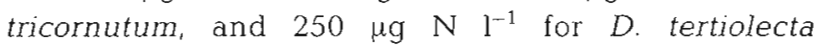
(Table 4).

\section{DISCUSSION}

\section{Factors influencing prey selectivity by Paraphysomonas imperforata}

According to Fenchel (1986) raptorial grazers can be distinguished from filter feeders, not only in their ability to graze large prey relative to their own size, but also in that they can discriminate prey on the basis of properties other than size alone. Chemosensory behavior is known to be widespread among protozoa (Van Houten et al. 1981), although, frequently, it is not easy to separate responses to chemical cues from those involving mechanoreception (e.g. size and shape). In the current experiments Paraphysomonas imperforata clearly favored the 2 smaller phytoplankton species Isochrysis galbana and Phaeodactylum tricornutum over the larger species Dunaliella tertiolecta, even though the chlorophyte was as acceptable a food source as either of the other 2 species when offered by itself (Table 2). Although specific growth rates $\mu$ of the flagellate were unaffected by any of the combinations of prey, the rates (mean $1.51 \mathrm{~d}^{-1}$ ), for reasons not fully explained, were lower than previously measured under similar experimental conditions (ca $2.5 \mathrm{~d}^{-1}$ ) (Goldman et al. 1985, 1987).

We have observed the problem of variable $\mu$ before (Goldman \& Caron 1985) and have suggested that cell aggregation seemed to be enhanced during the course of an experiment when the flagellate was preconditioned in the presence of bacteria, possibly leading to adhesion to surfaces and anomalously low cell count measurements and concomitantly low growth rates. No attempt was made to keep bacteria out of the preconditioning cultures, but since we did not observe any unusual cell aggregation during the experiments, cell aggregation does not appear to be a factor contributing to the lower growth rates observed. The fact that $\mu$ was internally consistent in the 13 experiments (Table 2). leads us to believe that the variability observed in $\mu$ for Paraphysomonas imperforata between these experi- 
Table 4. Prey cell concentrations $\left(T_{c}\right)$ and prey $N$ biomass $\left(T_{n}\right)$ for which ingestion rates were zero, and clearance rates for Paraphysomonas imperforata grazing on 3 phytoplankton species

\begin{tabular}{|c|c|c|c|c|c|c|}
\hline \multirow[t]{2}{*}{ Prey species } & \multirow[t]{2}{*}{$\mathrm{T}_{c}{ }^{\mathrm{s}}$} & \multirow[t]{2}{*}{$\mathrm{T}_{\mathrm{n}}{ }^{\mathrm{b}}$} & \multicolumn{4}{|c|}{ Clearance rate } \\
\hline & & & $\mathrm{C}^{\mathrm{c}}$ & $r^{2 d}$ & $V^{e}$ & $C^{\prime}$ \\
\hline Phaeodactylum tricornutum & 1.2 & 101 & 4.9 & 0.88 & 375 & 1.3 \\
\hline Isochrysis galbana & 0.4 & 57 & 7.5 & 0.81 & 525 & 1.4 \\
\hline Dunaliella tertiolecta & 0.6 & 250 & 2.8 & 0.64 & 1000 & 0.3 \\
\hline \multicolumn{7}{|c|}{ 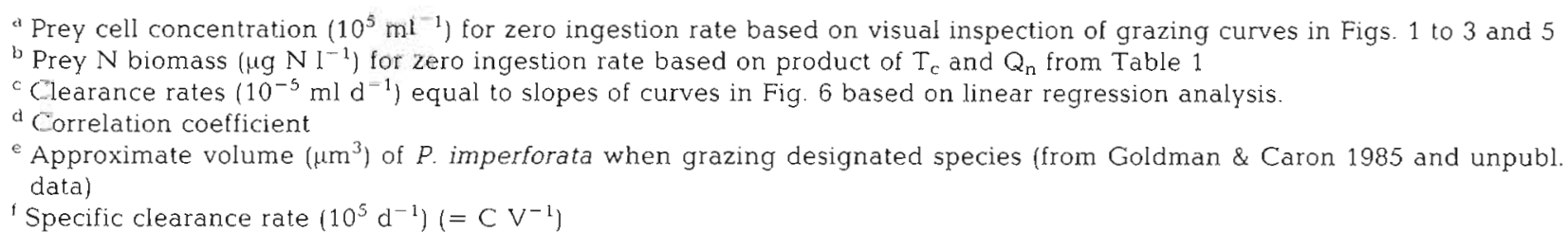 } \\
\hline
\end{tabular}

ments and our previous work is real and represents a physiological response to some unknown factor or perhaps a life cycle change. Although our strain of $P$. imperforata has been in culture since 1983, we do not believe the observed reduction in growth rate is the result of genetic drift. Specific growth rates have varied irregularly between the current values and ca $2.5 \mathrm{~d}^{-1}$ over this period (see Table 2 in Goldman \& Caron 1985). Nonetheless, since $\mu$ of the control cultures was virtually identical to those of the mixed prey cultures, the lower $u$ values probably had no effect on the patterns of prey selection by the flagellate.

The major question posed by our results is whether Paraphysomonas imperforata grazes by chemosensory responses or by mechanical reception. Several lines of evidence lead us to conclude that both grazing mechanisms may be involved simultaneously. In an earlier study (Goldman \& Caron 1985) we were able to show that when 11 different phytoplankton species were offered individually as prey to $P$. imperforata, 5 species spanning a size range from the small chlorophyte Nannochloris sp. (diameter $2 \mu \mathrm{m}$ ) to the large centric diatom Thalassiosira weissflogii (10 $x$ 14 um) were marginally ingested and did not support growth. The remaining 6 species along with bacteria, spanning a similar range of prey sizes as the unacceptable food sources and of different taxonomic groups and shapes, were readily grazed and all supported maximal growth rates. On this basis alone, it is evident that mechanoreception is not the only way in which the flagellate chooses food particles. Yet, in the current study, the evidence in favor of a chemosensory response to explain the preference for the smaller diatom and haptophyte over the Iarger chlorophyte is not so clear.

Flagellates feeding by direct interception can be likened to a spherical collector in a filter bed: the efficiency of grazing as measured by the specific clear- ance rate is proportional to the prey radius ( $r$ ) and inversely proportional to the square of the predator radius $(R)$, assuming spherical cells and $R \geqslant r$ (Fenchel 1986). Without the constraint that $R \geqslant$ I it can be shown that the specific clearance rate $C^{\prime}$ of a raptorial grazer is $0.75 \mathrm{v}\left(2 \mathrm{Rr}+\mathrm{r}^{2}\right) \mathrm{R}^{-3}$ where $\mathrm{v}$ is the predator's swimming speed. Although this type of approach is simplistic (Fenchel 1986), the relationship is instructive in highlighting some important general features of raptorial grazing. For example, from a resulting nomograph of $\mathrm{C}^{\prime}$ vs R: $\mathrm{r}$ for Paraphysomonas imperforata of different sizes [representing the effective diameters attained when grazing on each of the 3 test species (Table 4), that is, $\mathrm{R}=9 \mu \mathrm{m}$ (Phaeodactylum tricornutum), $\mathrm{R} \approx$ $10 \mu \mathrm{m}$ (Isochrysis galbana), and $\mathrm{R} \approx 12.5 \mu \mathrm{m}$ (Dunaliella tertiolecta)], and assuming a swimming speed of $100 \mu \mathrm{m} \mathrm{s}^{-1}, 2$ important points are easily visualized (Fig. 7). First, for each of the prey species, specific clearance rate $C^{\prime}$ is reduced asymptotically as $R: r$ increases. On this basis alone, not only can we see how raptorial grazing becomes increasingly inefficient as the ratio $R: r$ increases, but also that there is a dramatic increase in $C^{\prime}$ as $R: r$ decreases below ca 41 And second, when $R: r$ is constant $C^{\prime}$ increases as $R$ decreases. Thus from a hydrodynamic standpoint alone, it pays for a flagellate to alter its own size when grazing on prey species of different sizes so as to minimize R:I and thereby maximize $C^{\prime}$. Other protozoa, most notably the ciliates Didinium nasutum and Blepharisma, have been shown to possess a similar ability to alter their size so as to accomodate prey of different sizes (Giese 1973, Hewett 1980, 1988 and references cited therein).

Clearly, there must be a lower limit to R:r determined by the way in which engulfment takes place. For heterotrophic dinoflagellates it has been shown that R. $r \ll 1.1$ is possible, due to the unique way in which very large prey are captured and engulfed by the 


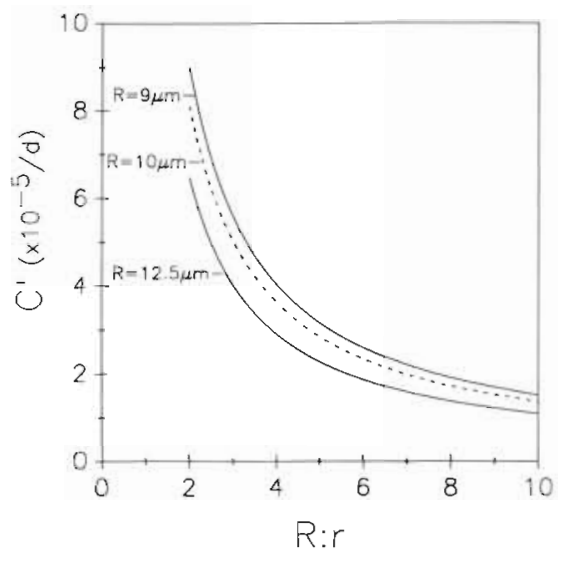

Fig. 7. Relationship between specific clearance rate $C^{\prime}$ and ratio of predator to prey radii $\mathrm{R}: \mathrm{I}$ for a raptorial grazer as described in text for predators of different radii

extention of pseudopod-like structures (Gaines \& Taylor 1984, Jacobson \& Anderson 1986). For Paraphysomonas imperforata virtually nothing is known of the way in which capture and engulfment of prey take place. However, based on our earlier studies, it appears that the lower limit to $\mathrm{R}: \mathrm{r}$ for this flagellate is ca $2: 1$ (Goldman \& Caron 1985). Although we did not measure the size of $P$. imperforata in the current experiments, the preference for Phaeodactylum tricornutum and Isochrysis galbana, 2 species of intermediate size, over the larger Dunaliella tertiolecta is not only predicted by the curves in Fig. 7 , since $C^{\prime}$ decreases as $R$ increases at a fixed value of $\mathrm{R}: \mathrm{r}$, but is also consistent with the trend in our estimates of $C^{\prime}$ (Table 4).

One puzzling aspect of our results was that there was no apparent saturation of the nitrogen ingestion rate $I_{n}$ at high levels of prey $\mathrm{N}$ (Fig. 6). The curves were generated by the combined data from each interval of grazing from the exponential through stationary phases, and not as is customarily done by measuring ingestion rate as a function of initial prey concentration during the exponential phase of separate experiments spanning a range of prey concentrations. Thus it may well be that ingestion rates at low prey $\mathrm{N}$ (concomitant with grazing well advanced into the exponential phase) were low due to a slowing of grazing resulting from factors related to the onset of unbalanced growth. If so, the resulting linearity in the ingestion curves for all 3 prey species (Figs. $6 \mathrm{~A}$ to $\mathrm{C}$ ) was fortuitous and the values of $\mathrm{C}^{\prime}$ reported in Table 4 are underestimates, a point consistent with the fact that these values are considerably lower than estimates of $C^{\prime}$ derived from the nomograph for each prey species with $\mathrm{R}: \mathrm{r}=2: 1$ (Fig. 7). Alternatively, the values of $C^{\prime}$ depicted by the nomographs in Fig. 7 are unrealistically high because a capture efficiency of $100 \%$ was assumed in developing the relationship between $C^{\prime}$ and $\mathrm{R}: \mathrm{r}$. In reality, capture efficiencies of raptorial grazers may be considerably lower that $100 \%$.

At the lower end of the size spectrum, the preference for a variety of phytoplankton species over bacteria may simply be due to the inability of the flagellate to reduce its own size below some lower limit (which we estimated to be ca $180 \mathrm{um}^{3}$; Goldman \& Caron 1985) so that specific clearance rates while grazing on bacteria always would be lower than when larger species were prey. Our earlier results showing higher $\mathrm{C}^{\prime}$ for Paraphysomonas imperforata when grazing on Phaeodactylum tricornutum compared to bacteria (Caron et al. 1985) support this conclusion and provide an explanation for why the flagellate seems to prefer the herbivorous mode.

While we can see that the food preference displayed by Paraphysomonas imperforata is explainable by consideration of hydrodynamic factors, there is still the unanswered question of how the flagellate makes a food selection as a mixed population of acceptable prey is being swept in flow lines that pass alongside of the organism's outer surface; for example, even though prey encounters with raptorial grazers are the result of random contacts, it was evident that the chlorophyte remained uningested in mixed populations with either of the other 2 species until these prey were grazed down to some lower level (Table 3; Figs. 2 and 3). Although we cannot discount the possibility of a chemosensory response, part of the reason for this avoidance may be due to the fact that the flagellate, by reducing its size to about 400 to $500 \mu \mathrm{m}^{3}$ in order to graze the smaller and preferred diatom or haptophyte (and thus increase its specific clearance rate), simply was too small to ingest the larger chlorophyte, which under these conditions was about half the volume of the flagellate. However, grazing on the chlorophyte commenced while there was still 30 to $60 \%$ of the diatom and 10 to $20 \%$ of the haptophyte cultures remaining (Table 3 ) and ingestion rates on these 2 prey, although falling rapidly, were still measurable (Figs. 2B, E and 3B, E). In fact, both smaller species continued to be grazed (albeit at slowing rates) along with the chlorophyte until grazing ceased. Thus if the small size of the flagellate alone was the only factor controlling the timing of the start of grazing on the chlorophyte, grazing on both of the smaller prey should have stopped first.

What triggered this change in the mode of grazing by the flagellate is impossible to determine with the data available. It would seem, though, that the flagellate, in some fashion (mechanical or chemical?), was able to sense the diminishing food supply of the smaller prey and the availability of the larger food source and make the switch to the latter. Possibly, this change in feeding strategy may be linked to the way in which ingestion 
rates on a nitrogen basis for the flagellate varied in 2 distinct phases, first falling rapidly during late exponential growth in the current experiments even before grazing on the chlorophyte took place, and then increasing as a function of the availability of the alternate food source (Figs. 2C, F, 3C, F and 4). During this period of changing ingestion rate, cell division continued uninterrupted, suggesting that there were concomitant changes in cell volume of the flagellate, first decreasing as the smaller prey was depleted and then increasing as the larger and less preferred food source was grazed and that the initial decrease in cell volume, perhaps to a limiting value of $R: r$, played a role in the switch to the larger prey. This conclusion is consistent with the fact that even though many protozoa including Paraphysomonas imperforata become smaller and reduce their respiration rates as a means of coping with starvation conditions when a particular food source is depleted and growth becomes unbalanced (Fenchel 1982a, Caron et al. 1985), they are able to renew grazing and get larger almost immediately upon being exposed to additional food (Fenchel 1982b). Fenchel (1987) describes this type of feeding, which is common among many raptorial grazers, as an adaptation to a feast or famine existence where the predator is always poised to exploit available food sources in order to avoid starvation. Our earlier observation of $P$. imperforata resorting to cannibalism after grazing a single phytoplankton food source with an increase in the size of a segment of the flagellate population (Goldman \& Caron 1985), is an extreme example of how the flagellate copes with changing food supplies.

While we can only speculate as to the mechanisms involved in the food selection patterns of Paraphysomonas imperforata, we can conclude that it, and probably many raptorial grazers, are tremendously opportunistic predators that, when faced with starvation conditions (e.g. depletion of a desired food source), can readily adapt to alternate food sources of varying sizes and shapes and maximize their grazing efficiency by adjusting the ratio $R: r$. Thus, while there is much evidence that food choices among raptorial grazers are influenced to some degree by chemosensory responses (e.g. Sibbald et al. 1987, Bennett et al. 1988), prey selection based on size (and probably shape) remains an important feeding strategy (e.g. Dubowsky 1974. Andersen et al. 1986)

\section{Grazing thresholds}

In our previous studies on grazing by Paraphysomonas imperforata (Caron et al. 1985, Goldman et al. 1987) and Oxyrrhis marina (Goldman et al. 1989) we concluded, based on our observations of what we believect to be threshold concentrations for grazing (ca $10^{4}$ to $10^{5}$ phytoplankton cells $\mathrm{ml}^{-1}$ or ca $10^{6}$ bacterial celis $\mathrm{ml}^{-1}$ ), that these 2 phagotrophs were restricted to grazing in productive waters or to microenvironments (e.g. marine snow) where prey concentrations were elevated considerably above ambient levels. This conclusion may not be entirely correct. Although threshold food levels for protozoan growth commonly have been observed (Taylor 1978, Rivier et al. 1985), and are consistent with the fact that a minimum food level represents the point at which the energy required for growth balances basal metabolic activity, the idea that actual grazing activity ceases when food levels reach a minimum level is not so easily explainable.

The concentrations of prey we have measured corresponding to zero ingestion rates always occurred at the end of exponential growth when predator and prey populations were about equal and not early in the growth phase under the general conditions of very low prey concentrations and far lower predator concentrations. The former conditions are similar to those found by Borsheim \& Bratbak (1987) and Geider \& Leadbeater (1988) for some bacterivorous flagellates and by Luckinbill $(1973,1974)$ and Salt $(1974,1979)$ in their studies on grazing of one ciliate (Paramecium) by another (Didinium). These latter researchers concluded that severe competition among predators for the relatively small number of prey at the tail end of batch growth led to starvation conditions which, in turn, caused reductions in swimming speeds and, concomitantly, to massive reductions in prey capture efficiencies. Thus some caution must be exercised in viewing our cell concentrations corresponding to zero grazing as true grazing thresholds in nature where prey populations generally exceeded those of their protozoan predators by orders of magnitude. There are, however, indications from other studies on both flagellates and ciliates that true grazing thresholds do exist (Davis \& Sieburth 1984, Rivier et al. 1985). Taylor (1978), in fact, did not discount the possibility that the thresholds for growth he measured for bacterivorous ciliates might be the net result of growth and grazing thresholds; he suggested that searching for food in a more enriched environment by protozoa might be an alternative to grazing very low food concentrations.

\section{Ecological importance of herbivory among flagellates}

Herbivory, as practiced by raptorial flagellates such as Paraphysomonas imperforata, may provide an important link in the microbial food loop first envisioned by Pomeroy (1974) and Azam et al. (1983). Because of their tremendous versatility in grazing a wide size range of prey and their ability to switch prey 
rapidly once a particular food source become scarce, raptorial grazers, including a variety of larger chrysomonads and dinoflagellates, may be effective competitors with ciliates for the nanoplankton size class ( 2 to $20 \mu \mathrm{m}$ ) of phototrophs and heterotrophs. In fact, $P$. imperforata is capable of grazing smaller bacterivorous flagellates (Goldman unpubl.). This would not only leave the smaller flagellates to graze bacteria, but contributes to making the food chain (web) within the microbial loop long and complicated with high losses of energy and materials (Caron et al. 1985, Goldman et al. 1985).

Acknowledgements. This study was supported by grants Nos. OCE-8511283 and OCE-8716026 from the National Science Foundation. We thank Dr A. F. Michaels for comments on the manuscript.

\section{LITERATURE CITED}

Andersen, O. K., Goldman, J. C., Caron, D. A., Dennett, M. R. (1986). Nutrient cycling in a microflagellate food chain: III Phosphorus dynamics. Mar. Ecol. Prog. Ser. 31: 47-55

Andersson, A., Larsson, U., Hagström, $\AA$. (1986). Size-selective grazing by a microflagellate on pelagic bacteria. Mar. Ecol. Prog. Ser. 33: 51-57

Azam, F., Fenchel, T., Field, J. G., Gray, J. S., Meyer-Reil, L. A., Thingstad, F. (1983). The ecological role of watercolumn microbes in the sea. Mar. Ecol. Prog. Ser. 10: 257-263

Barlow, R. G., Burkhill, P. H., Mantoura, R. F. C. (1988). Grazing and degradation of algal pigments by marine protozoan Oxyrrhis marina. J. exp. mar Biol. Ecol. 119: $119-129$

Bennett, S. J., Sanders, R. W., Porter, K. G. (1988). Chemosensory responses of heterotrophic and mixotrophic flagellates to potential food sources. Bull. mar Sci. 43: 764-771

Borsheim, K. Y., Bratbak, G. (1987). Cell volume to cell carbon conversion factors for a bacterivorous Monas sp. enriched from seawater Mar. Ecol. Prog. Ser. 36: 171-175

Caron, D. A., Goldman, J. C., Andersen, O. K., Dennett, M. R. (1985). Nutrient cycling in a microflagellate food chain: II Carbon cycling and population dynamics. Mar. Ecol. Prog. Ser 24: $243-254$

Caron, D. A., Goldman, J. C., Dennett, M. R. (1986). Effect of temperature on growth, respiration, and nutrient regeneration by an omnivorous microflagellate. Appl. environ Microbiol. 52: 1340-1347

Davis, P. G. Sieburth, J. McN. (1984). Estuarine and oceanic microflagellate predation of actively growing bacteria: estimation by frequency of dividing-divided cells. Mar. Ecol. Prog. Ser. 19: 237-246

Dubowsky, N. (1974). Selectivity of ingestion and digestion in the chrysomonad flagellate Ochromonas malhamenis. J. Protozool. 21. 295-298

Fenchel, T (1982a). Ecology of heterotrophic microflagellates. II. Bioenergetics and growth. Mar. Ecol. Prog. Ser. 8: 225-231

Fenchel, T. (1982b). Ecology of heterotrophic microflagellates III. Adaptations to heterotrophic environments. Mar. Ecol. Prog. Ser. 9: 25-33

Fenchel, T. (1986). Protozoan filter feeding. In: Corliss, J. O.,
Patterson, D. J. (eds.) Progress in protistology, Vol. I. Biopress, Bristol, p. 65-113

Fenchel, T. (1987). Ecology of protozoa. Science Tech. Inc., Madison

Gaines, G., Taylor, F. J. R. (1984). Extracellular digestion in marine dinoflagellates. J. Plankton Res. 6: 1057-1061

Geider, R. J., Leadbeater, B. S. C. (1988). Kinetics and energetics of growth of the marine choanoflagellate Stephanoeca diplocostata. Mar. Ecol. Prog. Ser 47-169-177

Giese, A. C. (1973). Blepharisma. Stanford Univ. Press, Stanford

Goldman, J. C., Caron, D. A. (1985). Experimental studies on an omnivorous microflagellate: implications for grazing and nutrient regeneration in the marine microbial food chain. Deep Sea Res. 32: 899-915

Goldman, J. C., McCarthy, J. J. (1978). Steady state growth and ammonium uptake of a fast-growing marine diatom. Limnol. Oceanogr 23: 695-703

Goldman, J. C., Caron, D. A., Andersen, O. K., Dennett, M. R. (1985). Nutrient cycling in a microflagellate food chain I. Nitrogen dynamics. Mar Ecol. Prog. Ser 24: 231-242

Goldman, J. C., Caron, D. A., Dennett, M. R. (1987). Nutrient cycling in a microflagellate food chain: IV Phytoplanktonmicroflagellate interactions. Mar. Ecol. Prog. Ser. 38: $75-87$

Goldman, J. C., Dennett, M. R., Gordin, H. (1989). Dynamics of herbivorous grazing by the heterotrophic dinoflagellate Oxyrrhis marina. J. Plankton Res. 11: 391-407

Güde, H. (1985). Influence of phagotrophic processes on the regeneration of nutrients in two-stage continuous culture systems. Microb. Ecol. 11· 193-204

Hewett, S. W. (1980). Prey-dependent cell size in a protozoan predator. J. Protozool. 27 311-313

Hewett, S. W. (1988). Predation by Didinium nasutum: effects of predator and prey size. Ecology 69: 135-145

Hibberd, D. J. (1979). Notes on the ultrastructure of the genus Paraphysomonas (Chrysophyceae) with special reference to P. bandaiensis Takahashi. Arch. Protistenk. 121: 146-154

Jacobson, D. M., Anderson, D. M. (1986). Thecate heterotrophic dinoflagellates: feeding behavior and mechanisms. J. Phycol. 22: 249-258

Luckinbill, L. S. (1973). Coexistence in laboratory populations of Paramecium aurelia and its predator Didinium nasutum. Ecology $54: 1320-1327$

Luckinbill, L. S. (1974). The effects of space and enrichment on a predator-prey system. Ecology 55: 1142-1147

Parslow, J. S., Doucette, G. J., Taylor, F. J. R., Harrison, P. J. (1986). Feeding by the zooflagellate Pseudobodosp. on the picoplanktonic prasinomonad Micromonas pusilla. Mar Ecol. Prog. Ser. 29: 237-246

Pomeroy, L. R. (1974). The ocean's food web: a changing paradigm. BioScience 24: 499-504

Ramberg, L. (1987). Grazing by a colourless flagellate on a green algal bloom. Schweiz. Z. Hydrol. 49: 294-302

Rivier, A., Brownlee, D. C., Sheldon, R. W., Rassoulzadegan, F. (1985). Growth of microzooplankton: a comparative study of bactivorous zooflagellates and ciliates. Mar. Microb. Food Webs 1: 51-60

Salt, G. W. (1974). Predator and prey densities as controls of the rate of capture by the predator Didinium nasutum. Ecology 55: 434-439

Salt, G. W. (1974). Density, starvation, and swimming rate in Didinium populations. Am. Nat. 113: 135-143

Sherr, B. F., Sherr, E. B., Hopkinson, C. S. (1988). Trophic interactions within pelagic microbial communities: indications of feedback regulation of carbon flow. Hydrobiologia 159: $19-26$ 
Sibbaid, M. J., Albright, L. J., Sibbald, P. R. (1987). Chemosensory responses of a heterotrophic microflagellate to bacteria and several nitrogen compounds. Mar. Ecol. Prog. Ser. 36: 201-204

Suttle, C. A., Chan, A. M., Taylor, W. D., Harrison, P. J. (1986).

Grazing of planktonic diatoms by microflagellates. J. Plankton Res. 8: 393-398

This article was submitted to the editor
Taylor, W. D. (1978). Growth responses of ciliate protozoa to the abundance of their bacterial prey. Microb. Ecol. 4: $207-214$

Van Houten, J., Hauser, D. C. R., Levandowsky, M. (1981). Chemosensory behavior in protozod. In: Levandowsky, M., Hunter, S. H. (eds.) Biochemistry and physiology of protozoa, Vol. 4. Academic Press, New York, p. 67-124

Manuscript first received: May 3, 1989

Revised version accepted: September 12, 1989 